Revista Portuguesa de História

t. XXXI, Vol. I(1996)

\title{
PARA A HISTÓRIA DA AUTONOMIA DOS AÇORES - A INTRODUÇÃO FORÇADA DA FISIOCRACIA NO ARQUIPÉLAGO
}

JOÃO MARINHO DOS SANTOS

(Universidade de Coimbra)

A 26 de Fevereiro de 1771, um alvará assinado pelo Marquês de Pombal decretava que, de futuro, seria «livre a extracção dos referidos trigos das Ilhas dos Açores para esta Cidade de Lisboa em beneficio commum da Capital do Reino [...]», exceptuando somente a situação "em que se verifique falta de trigos para o sustento dos moradores das respectivas Ilhas, no qual caso as Cameras farão praticar provisionalmente a reserva da terça parte [...]»'. Além de Lisboa, continuaria a ser abastecido o arquipélago da Madeira, já que a praça de Mazagão, no Norte de África, historicamente também provida, acabava de ser evacuada (1769). Entre as considerações circunstanciais ou enquadradoras do referido diploma (já que o Poder Central não duvidaria da forte contestação que ele suscitaria no arquipélago), referiam-se os «intoleraveis monopolios de trigos que se faziam nas ilhas dos 
Açores a beneficio dos officiais das respectivas Cameras e de outras Pessoas poderosas» e o reconhecimento que as ilhas eram «adjacentes» do Reino, ou seja, províncias suas e, nestas, o «pão» era comercializado para «onde [as pessoas] querem, e mais interesse lhes faz».

Comentemos uma e outra destas considerações.

Quanto à primeira, ela era sem dúvida verdadeira e tanto mais pertinente quanto se tratava de uma circunstância com quase três séculos de história. Efectivamente, da leitura do regimento de um comissário, encarregado de comprar para a Coroa/Estado, em 1507, trigo em S. Miguel, depreende-se a existência já de um contencioso que o rei procurava resumir e resolver deste modo:

a) Perante o costume dos oficiais das câmaras venderem primeiro o seu trigo e depois embargarem o comércio externo deste cereal, «cerrando os portos», para lograrem comprar entretanto por baixo preço o trigo dos «pequenos» e voltarem a abri-los (com lucros manifestos), fosse declarada a liberdade de cada um vender em qualquer tempo;

b) Para contemplar as necessidades da(s) ilha(s), um argumento invocado para reter parte da renda dos lavradores absentistas e cerrar os portos, que se orçasse, anualmente, no tempo da debulha, a quantidade de trigo necessária e se satisfizesse, passando o excedente a ser objecto de comércio livre.

Ficou a questão sanada? É claro que não e porquê? A obrigatoriedade de ficar na «terra» uma percentagem da produção tritícea proporcionava aos grandes lavradores - comerciantes («atravessadores»), através de conluios com as vereações dos concelhos, o clientelismo (muito apreciado em termos de status) e o oportunismo mercantil. De facto, entre outras irregularidades que prejudicavam a seriedade com que deveria ser feito o exame/avaliação anua! 
do trigo («trigo do exame») eram imputadas, à (quase) totalidade das câmaras, estas: não sacarem trigo a todos os «lavradores», isentando os que eram das suas simpatias; tomarem o trigo no verão e só o pagarem um ano depois; receberem-no pelo valor corrente (normalmente baixo) e, passado pouco tempo, empolarem os preços com o mecanismo do «cerrar dos portos», conforme foi dito.

Ia-se formando assim (não apenas, obviamente, com o concurso do comércio dos grãos) uma elite local que poderemos classificar de bipartida, ou seja, de natureza terratenente/agrária e mercantil, fortemente apoiada pelo terciário eclesiástico. Para controlar, minimamente, as suas aspirações e os seus interesses, a Coroa/ Estado dispunha do poder legislativo (mas com o respectivo normativo a ser, frequentemente, cerceado e até deturpado pelas posturas municipais) e da actuação (difícil) do(s) corregedor(es) em serviço no arquipélago. Por sua vez, o grupo dos «lavradores —atravessadores» procurava atirar com o odioso da saca do «pão» para cima dos lavradores absentistas e do principal arrecadador das rendas (sobretudo a partir do momento em que o poder donatarial passou a coincidir com o poder real), ou seja, da Coroa. Em suma, será esta a realidade que, mutatis mutandis, persistirá até à publicação do alvará de 26 de Fevereiro de 1771.

Com este diploma o que é que mudava ou se procurava mudar?

$\mathrm{O}$ que, explicitamente, é dito é que eram «intoleraveis» os monopólios do trigo por parte da elite que pontificava nos Açores, preconizando-se, portanto, o livre comércio. Mas, tratar-se-ia, efectivamente, de um comércio livre? Obviamente que não, já porque persistia a «reserva da terça parte» quando se constatava que ela era localmente necessária; já porque se devia garantir «os provimentos, que fossem necessarios para o socorro dos morado- 
res da ilha da Madeira»; já porque (e sobretudo), a partir daquela data, só ficava "geral, e livre a extracção dos referidos Trigos das Ilhas dos Açores para esta Cidade de Lisboa em beneficio commum da Capital do Reino».

$\mathrm{O}$ que o citado diploma não dizia era que, naquela conjuntura, Lisboa tinha sérias dificuldades em obter o «trigo do Norte» da Europa (recebido sobretudo de e por intermédio da França), uma alternativa que a Coroa/Estado, em anos normais, não enjeitava por ser económica e politicamente mais vantajosa. Viviam-se, efectivamente, já os anos conturbados que levariam à «Revolução Francesa» e era natural, portanto, que (mais uma vez) o mercado externo se ressentisse. Ora, esta situação era secular e vinha confirmar quanto, em matéria alimentar, o nosso País era altamente dependente do estrangeiro. A propósito e apenas com carácter exemplificativo, veja-se o testemunho de Francisco Manuel da Costa, contido na sua Dissertação sobre a livre importação de cereaes estrangeiros em Portugal (1860): «[...] a subsistencia do povo estará á mercê dos estrangeiros que quando lhes parecer, podem estabelecer o monopólio, fixando os preços, que bem quizerem, e ter o paiz debaixo da sua dependencia, e no caso de sobrevir um anno de esterilidade, ou de se dar algum obstaculo, que embarace o indispensavel fornecimento, a fome apparecerá com todos os seus horrores, e o povo será victima da sua imprevidencia». Aliás, segundo este arbitrista, no decénio de 1778 a 1787, foram vendidos no Terreiro Público de Lisboa cereais estrangeiros no valor de $16112527 \$ 639$ rs, enquanto os do reino e das ilhas tinham suportado transacções que se haviam cifrado apenas em $6076587 \$ 385$ rs.

Quão longe estava este alvitre de um outro proferido por José Acúrsio das Neves no ano de 1800: «Com tanto grão, pois, e com 
tantas facilidades nadafalta à Europa senão a inteira liberdade do comércio do mesmo grão para que todos os seus habitantes sejam bem fornecidos dele»².

Voltando, porém, à questão cerealífera que tinha como centro produtor os Açores, registe-se que, a 5 de Novembro de 1786, era publicado um aviso real em que se determinava a liberalização do comércio local do trigo e do milho. E, cerca de três anos mais tarde, ou seja, a 20 de Agosto de 1789, um outro aviso da Secretaria de Estado com base na «toda a certeza» de que se verificariam perturbações nas regulares importações dos grãos, determinará que se declarasse, imediatamente, a «livre exportação» para Lisboa (sempre a preocupação de abastecer a capital!) de todos os grãos produzidos no arquipélago, sem ser necessária a passagem de qualquer licença camarária ${ }^{3}$. Aliás, já então se vinha verificando a entrada, nas ilhas açorianas, de farinhas e outros comestíveis provenientes de Cabo Verde e da América Inglesa, o que, naturalmente, era bem visto pelo Governo de Lisboa.

Em contraponto, no entanto, o arquipélago (com particular destaque para a ilha de $S^{\text {ta }}$. Maria) experimentava, pontualmente, séria escassez de mantimentos, pelo que um outro aviso da Secretaria de Estado, datado de 13 de Novembro de 1789, voltava a suster a livre exportação dos grãos. Era, sem dúvida, o pragmatismo a sobrepor-se à disposição normativa, ainda que se proclamasse que, com preços convenientes e a pronta saída dos frutos da terra, os lavradores açorianos experimentariam consideráveis melhoras na agricultura local. Ou seja, a atitude liberal do governo

In «Archivo dos Açores», vol. V, pp. 288-290. 
de Lisboa conhecia uma pausa, mas não ameaçava desistência. Tanto assim que, a 10 e 15 de Fevereiro de 1790, era comunicada, respectivamente, ao Capitão General e ao Corregedor dos Açores, «estranheza» por não haver já sido restabelecida a liberdade de circulação dos grãos.

Que a reacção da elite insular a estas determinações do Governo Central era firme e alargada prova-o o arrojo do Capitão General de considerar «indiferente» para o estado e o futuro da agricultura do arquipélago a livre circulação dos cereais, em oficio de 14 de Janeiro de 1790. Lisboa apressar-se-á a corrigi-lo. Mas, alarguemos os campos da observação e da explicação.

Conforme se sabe, um dos aspectos a que o mercantilismo conferiu particular importância foi o da moeda. Em princípio, os mercantilistas eram monetaristas, o que significa que não bastava que a moeda fosse abundante, antes que fosse também «boa», ou seja, que tivesse um poder constante numa área de influência tão alargada quanto possível com vista a estimular o comércio externo/ grande comércio. Em Portugal, segundo Vitorino Magalhães Godinho, no último quartel do século XVIII e na primeira metade do século XIX, a elite/facção tradicional «define a riqueza pela moeda e busca garantir a maior quantidade de numerário (cunhado nos metais preciosos) graças sobretudo ao incremento comercial e a certas restrições aduaneiras»".

Nos Açores, como aliás em outros «senhorios/donatarias», estava estabelecido que um dos direitos reais a observar deveria ser a obrigatoriedade da moeda corrente ser a cunhada no Reino, ainda que este princípio nem sempre fosse cumprido. Com efeito,

'Estrutura da Antiga Sociedade Portuguesa. Lisboa. Editora Arcádia, 1975 119-120. 
o fluxo monetário a partir de Portugal manteve-se, por morma, extremamente débil e os «atravessadores» locais, fiéis a alguns princípios do mercantilismo, retinham a pouca moeda reinol e, para os seus negócios com o estrangeiro, recorriam, o mais possível, aos «reales» e às letras de câmbio. Assim, quando, concretamente, a guerra estalou entre o Prior do Crato e Filipe II e o primeiro decidiu bater moeda em Angra, algumas relações informam que havia, então, na Terceira «muy poco dinero y pastel» ou havia pouco dinheiro mas «muitas peças de oiro e prata». A esta abundância metalista não era estanha (antes pelo contrário e como se sabe) a obrigatoriedade (por condicionalismos geográficos e tecnológicos) das rotas da América espanhola contemplarem os Açores e de a política financeira dos nossos vizinhos não ser de molde a fixar internamente a prata e até o ouro. Dos Açores, por contrabando os metais preciosos chegavam, em boa percentagem, a Lisboa e, como dirá o embaixador de Castela, por meados da era de Quinhentos, vinham os franceses, flamengos e outros com trigo à capital do Império português, para satisfazer «la gran falta y ambre que en toda esta tierra ay» $\mathrm{e}$ levavam os «reales» e a «moeda nova» (valorizada) portuguesa, opinando «que la una e la otra se saca por aqui para Francia y para Flandes».

De qualquer modo, muita da «boa» moeda também deveria estar retida nas mãos dos «atravessadores» açorianos e, para a sua sensibilidade monetarista, imagine-se o efeito do edital, de 24 de Fevereiro de 1793, ao impor os «bilhetes» (papel moeda com o valor declarado de $4 \$ 800$ rs) e a circulação de uma moeda metálica de má qualidade. Antes mesmo de registarmos algumas reacções a esta decisão, adiantemos que para os mercantilistas (teóricos e práticos) dos Açores o referido edital passará a ser o 
bode expiatório de todas as desgraças locais.

Quanto às reacções, e em particular à imposição dos «bilhetes», retenha-se este parecer [de D. Antão de Almada?], em carta redigida em 1794: «Os bilhetes são o golpe maisfatal, que pode vir a todas estas Ilhas [...] Sua Magestade tem dado nestas Ilhas estes Bilhetes a troco de prata pelo seu peso e valor real; agora se sua Magestade mandasse que estes Bilhetes se fossem recolhendo á sua real fazenda, e que não tomassem a sair nem a circular, teria feito a felicidade das Ilhas, sem nada perder; [...] pois ainda no caso de faltar dinheiro seria mais vantajoso suprimir a circulação dos Bilhetes, e que as compras se fizessem por algum tempo e em algumas occasiões a troco de generos, na cereteza de que o commercio (unico meio de remediar estasfaltas) buscaria logo introducção da moeda em abundancia, como genero de maior necessidade no paiz...». Ou seja, em vez dos «bilhetes» como elemento mediador do comércio interno, era preferível a troca directa.

Por sua vez, lê-se em uma representação da Câmara de Angra, de 22 de Julho do mesmo ano, dirigida ao Governo Interino dos Açores: «E origem de todas essas oppresões a desordem que se vê e descobre na moeda que apparece, porque sepultada, supprimida, ou talvez transtornada a que corria, toda de prata e essa legitima ainda que muito e demasiadamente cerceada, não se vê mais que uma moeda chamada tostão, seus cunhos claros, e na sua maior parte de metaes differentes, e sem valor intrinseco que possa exceder a vintem e trinta reis conhecendo-se bem e claramente serfundida efabricada por individuos esquecidos de ser catholico e christão e até dos preceitos da humanidade, para que 
toda a nação sempre olha $[\ldots] »^{6}$.

Estava, pois, identificado o partido dos «fabricantes da moeda falsa», capciosamente apontados como herejes e desumanos, responsáveis pela subida dos «jornaes [salários] dos trabalhadores, dos artifices, dos officiaes de todos os officios, e até dos materiaes para quaesquer obras; e nenhum effeito contra tanta desordem se poderá conseguir, sem que seja por uma providencia sobre a moeda $[\ldots] »^{7}$.

A apologia do comércio (sobretudo do comércio externo) e dos seus benefícios foi, como se sabe, suficientemente glosada pelos mercantilistas. Por exemplo, em 1622, Thomas Mun, no seu England's Treasure byforeign Trade apregoará que «[...] $o$ comércio externo é a riqueza do soberano, a honra do reino, a nobre vocação dos mercadores, a nossa subsistência e o emprego para os nossos pobres, o melhoramento das nossas terras, a escola dos nossos marinheiros, o nervo da nossa guerra, o terror dos nossos inimigos». Deste modo, o comércio por grosso era uma profissão honrosa, perfeitamente conciliável com o status nobre e acarinhada pela hierarquia da Igreja Católica. No que concerne aos efeitos da «má moeda» sobre os preços e os salários e a ordem social, é também sabido que o mercantilismo se esforçou por fixar os salários, manter as remunerações muito abaixo dos preços alimentares e industriais (logrando assim uma mão-de-obra barata) e combater a vagabundagem, a mendicidade e outras formas de «esordem».

Nos Açores, a situação não foi muito diferente da de outras

Apud Pierre Deyon, O mercantilismo, trad., Lisboa, Gradiva, 1989, p. 66. 
regiões da Europa. A elite terratenente-mercantil, para além de utilizar o «cerrar dos portos» como forma de artificializar os preços, em particular dos cereais, usufruindo assim de chorudos lucros em nome da assistência à pobreza local, usou a «terça do pão» como regulador social. Explicitando: impôs salários por norma baixos para obrigar os sem terra a trabalharem, controlou também a vagabundagem e a mendicidade (não se esqueça a sua forte influência sobre as vereações) e doseou a torneira da reserva do trigo para situar a pobreza ao nível próximo da necessidade das saídas. Ou seja, proporcionava uma maior oferta do «pão» quando ouvia e sentia crescer o clamor dos que tinham fome, para logo a refrear quando a procura interna tendia a aumentar. Deste modo, só quando determinadas catástrofes naturais (tremores de terra, erupções, fortes chuvadas...) atiravam com indivíduos e famílias (quando não «freguesias» inteiras) para a indigência é que os Poderes locais estimulavam a emigração, ou antes, a colonização, tendo como destino normal o Brasil. Foram transferidos assim, para o «Novo Mundo», muitos reprodutores humanos, saberes e técnicas a partir do arquipélago.

Pensamos estar explicitada e explicada, em boa parte, a situação de «desordem» que a liberalização (ou a dita liberalização) dos grãos e a introdução de novas espécies monetárias (com relevo para o papel-moeda) vieram provocar nos Açores a partir dos anos 70 de Setecentos. Quanto aos adeptos ou defensores do mercantilismo e do liberalismo económico/fisiocratismo, não será difícil, pelo que até agora se disse, identificá-los por grupos/categorias. Alinharão pelo partido vigente os «atravessadores» (grandes mercadores e terratenentes enobrecidos), as câmaras e a maior parte do clero (com relevo para o alto clero). Defenderão o liberalismo/o movimento fisiocrata prematuro os grandes rendeiros e 
os tratantes sem terras e sem títulos nobiliárquicos, ou seja, os «negociantes» como eram depreciativamente designados pelos seus opositores. Aparentemente e até na realidade este «partido» era fraco, mas não se esqueça que contava, pontualmente e por oportunismo centralizador, com o apoio da Coroa/Estado.

Individualmente, ao nível do Governo Interino dos Açores e no ocaso do século XVIII, representava o primeiro partido o Bispogovernador, dava a cara (ainda que a contra-gosto) pelo segundo o Desembargador-corregedor. A 16 de Setembro de 1794, os governantes locais reuniram para tomar posição sobre a nova moeda e ganhou a facção que, oficialmente, defendia o liberalismo/ fisiocratismo.

Quanto às respectivas estratégias, em termos teóricos e práticos, elas assentavam no seguinte:

Para os mercantilistas, a má moeda («moeda falsa») era responsável pela carestia dos preços e, consequentemente, pela fome, já que não concitava a confiança dos agentes económicos e não era suficiente para, «com certeza e fidelidade», estimular o comércio externo e, em particular, o dos grãos. Com efeito, o «papel» e o novo «metal» estavam a fazer com que a «serrilha» e a «pataca castelhana» (de boa prata) tendessem a desaparecer da circulação. Dito de outro modo, incrementava-se o entesouramento à custa da «boa moeda» e, como a massa metálica em circulação era escassa e de pouco crédito, os negócios enquistavam.

Mais: os mercantilistas não prescindiam do «trigo do exame» e da reserva da «terça parte», exigindo, além disso, que as câmaras passassem as respectivas licenças para alguém poder exportar. Claro está que estas não as passavam aos «negociantes» e, quanto ao «trigo do exame» para se estabelecer a «reserva», também era óbvio que a subjectividade pesava. Daí que o Governo Central 
insistisse que a ratio da «reserva» deveria ser estimada em 30 alqueires por pessoa, devendo o excedente ser liberalizado para acudir à Madeira e à capital do Reino. $\mathrm{O}$ cumprimento ou não desta ordem poderia ser controlado através de inquéritos sobre o estado das searas, dos stocks das colheitas e da entrada obrigatória de todas as embarcações provenientes dos Açores no porto de Lisboa (cf. aviso de 27 de Abril de 1795)'.

A 13 de Julho de 1797, a elite terratenente-mercantil das ilhas açorenses recebia novo golpe nos seus interesses. Por decisão de Lisboa, de futuro os trigos destinados à Fazenda Real deveriam ser medidos no acto do embarque e pelas medidas usadas na compra ao produtor. Procurava-se, deste modo, acabar ou, pelo menos, cercear certos abusos tradicionais: percentagens dos «comissários» (alguns residentes), alegadas quebras entre a compra e o embarque, diferenças de medidas (quer quanto à capacidade, quer quanto à convenção de serem «rasas» ou de «cogulo»)... Os mercantilistas iam acusando os toques e respondiam com a recusa da aceitação dos «bilhetes», (alegando, nomeadamente, que não havia «bilhetes miúdos», nem moeda de bulhão). Presionavam, ainda, com a ameaça ( «susto») de haver fome generalizada nas ilhas, por desconhecimento da situação interna e pelo grande afã em exportar. Individualmente, destacar-se-ão as posições de algumas figuras açorianas, como a do juiz de fora da Graciosa, ao proibir, em 1799, a livre exportação dos grãos e ao fazer tábua rasa das recomendações do Governo Central para que se divulgasse, entre os pobres, que a esterilidade da agricultura se devia à falta de preços livres. É que, tempos antes, mais propriamente a 11 de Julho do referido ano, tinha sido imposto às câmaras 
açorianas que deixassem de taxar os preços dos grãos e de outros géneros comestíveis, compreendendo-se perfeitamente o alcance desta medida como contrária à política dos mercantilistas. O juiz foi admoestado.

O século XVIII fechava assim, nos Açores, com uma assinalável perturbação política. Para a enquadrar, talvez valha a pena lembrar o seguinte:

Durante a era de Setecentos a população portuguesa aumentou cerca de 50\% (de 2 milhões de indivíduos no início da centúria passou para 3 milhões, aproximadamente, no final), com Lisboa a contabilizar à volta de 200 mil habitantes. Este crescimento populacional exigiu mais importações cerealíferas, ainda que tenha havido, também, um aumento da cerealicultura nacional, a par aliás da pastoricia e de outras culturas comercializáveis.

A política oficial portuguesa será tipicamente mercantil, assistindo-se à preocupação de reter o ouro, para que a abundância dos metais preciosos (não inteiramente coincidente com uma maior riqueza) pudesse assegurar a prosperidade da Nação e o poder do Estado. Aliás, a influência do ouro teve, certamente, reflexo no aumento dos preços e, em finais dos anos 70, com alguns problemas a afectarem a rede de «companhias», enveredou-se pela liberalização do comércio. Relativamente ao abastecimento cerealífero, o Governo Central assumiu o controlo directo das importações e, quanto à produção nacional, respeitou (não apenas nos Açores, mas também nos concelhos do Reino) a constituição de «terças» para abastecimento local. Contudo, e como se disse, a guerra entre a Grã Bretanha e a França «revolucionária» prejudicou o ensaio (precoce) do liberalismo económico. Seguiu-se a Guerra Penisular entre 1807 e 1814, pelo que a recuperação monetária só se verificou a partir de 1830 e a financeira depois de 1850 . 
Regressemos, porém, aos Açores. Em 1805, o muito «bicho» comeu o milho e as chuvas intensas dizimaram grande parte das searas de trigo na costa norte da ilha de S. Miguel. Tal situação foi aproveitada pelas câmaras locais para impedirem a livre exportação dos grãos e voltarem mais decididamente ao regime dos condicionamentos das licenças, conforme se poderá comprovar por um acordão e edital da câmara de Ponta Delgada, de 29 de Outubro de 1805.

Os dois anos seguintes foram, porém, bastante favoráveis à produção e só então se deu a necessária divulgação do aviso de 27 de Abril de 1795 (!). Ou seja, só então os mercantilistas começaram a ceder publicamente, embora continuassem a actuar de uma forma muito pragmática. Com efeito, no acordão e no edital de 1805, aceitava-se, teoricamente, que a liberdade do comércio pudesse ser a causa principal da riqueza das Nações, para logo se afirmar que não se podia ir contra as Leis do Reino e estas (designadamente as Ordenações e os Costumes locais) estabeleciam que os exportadores de cereais tinham de pedir autorização às câmaras.

Do ponto de vista das doutrinas/da teoria económica há nestes diplomas referências mais implícitas do que explícitas a uma evolução. O mercantilismo clássico (designadamente sob a forma do Colbertismo) há muito que já tinha os seus opositores declarados e cada vez em maior número. Proclamava-se, em suma, que a criação da riqueza assentava no livre mecanismo dos preços ou, como dirá Boisguilbert na sua Dissertation sur la nature des richesses..., «assim que for posta em liberdade, a mesma natureza [...] restabelecerá o comércio e a proporção de preços entre todas as mercadorias $»^{10}$. Enfim, neste aspecto, era um precursor dos 
fisiocratas, preludiando, portanto, o alargamento da liberdade dos mercados (através do jogo da oferta e da procura) à própria produção. Por sua vez, J. Child provará e defenderá que os salários altos eram mais favoráveis ao crescimento e ao desenvolvimento do que os baixos. Em 1757, Quesnay no artigo «GRAINS», publicado na Encyclopédie, como se sabe, criticará os mercantilistas por terem descurado a agricultura...Depois, Adam Smith depreciará o «sistema mercantil»e, entre outras condenações, proclamará que os privilégios concedidos às manufacturas eram tão negativos como o exclusivo colonial, ou seja, a obrigatoriedade das colónias só exportarem para as respectivas metrópoles.

Não está nas intenções deste artigo (necessariamente bastante limitado) relembrar os reflexos ou as repercurssões da evolução das doutrinas económicas em Portugal, mas tão só captar o diálogo (ou o não diálogo) entre Governo Central e as «autoridades» (com os seus «partidos» nos Açores).

Porém, e porque se julga de interesse para o fim em vista, com o auxílio de Vitorino Magalhães Godinho, sempre lembraremos que a política económica, preconizada, por exemplo, por Azeredo Coutinho, em finais de Setecentos_começos de Oitocentos, entre outros pontos defenderá estes : «manutenção firme do Pacto Colonial (mas a ela renunciará na 2- edição [do seu Ensaio Económico sobre o Comércio de Portugal e suas Colónias], de 1816) e liberdade económica na metrópole e, quanto únicamente à agricultura, no Ultramar»".

Relevamos estes dois eixos, por se nos afigurarem essenciais nas relações entre o arquipélago dos Açores e a mãe-pátria durante o período que estamos a considerar. No que concerne ao jogo de 
reacções a nível local, passamos a lembrar a posição, divulgada a 2 de Março de 1807, do juiz de fora de Ponta Delgada. Proporá ele que fosse impedido o embarque do milho micaelense antes de Março de cada ano, por se verificarem três vantagens: os pobres teriam a sua subsistência garantida durante o «inverno» insular; os comerciantes exportariam o cereal completamente seco (diminuido-se assim os riscos do transporte marítimo); e já então o Reino teria consumido a sua própria produção.

Era uma posição aparentemente conciliadora, mas obviamente contrária à total liberdade do comércio, como o era, afinal (recordemo-lo, agora, com mais pertinência), a obrigatoriedade das exportações cerealíferas do arquipélago só contemplarem o Reino e a Madeira. Não admira, pois, que os «lavradores»e «negociantes» de S. Miguel partidários da fisiocracia, em Novembro do mesmo ano, tivessem contestado a referida proposta, afirmando que o condicionamento das exportações até Março de cada ano prejudicava tudo e todos, uma vez que agravaria a questão do armazenamento (um problema crónico nas ilhas), dificultaria aos rendeiros o pagamento das rendas em dia de todos os Santos e favoreceria a concorrência, no Reino, dos milhos americanos (os quais chegavam a Lisboa, por norma, no começo da Primavera).

Repare-se, porém, como a conjuntura já era outra ao verificarse o incremento da oferta cerealífera em Lisboa (à custa sobretudo dos Estados Unidos da América) e ao tornar-se difícil a colocação dos «trigos» (e doutros cereais) das ilhas açorenses. Concretamente, em 1807, verificou-se uma abundante colheita de milho nos Açores, os compradores não aumentaram, os preços tenderam a descer e as áreas cultivadas correram o risco de se converter em áreas de pasto.

Enfim, era uma boa situação para os «fisiocratas» contra- 
atacarem. E fizeram-no. Afirmaram, alto e bom som, que a obrigatoriedade da passagem de licenças camarárias para exportação dissuadira os mercadores alógenos de comprarem os cereais e, por tal, a «boa moeda» não entrava. Logo, havia que cumprir, localmente, a «sábia» Lei de 26 de Fevereiro de 1771 e a Ordem real de 20 de Agosto de 1789. Durante o curto prazo em que tais diplomas foram observados, os preços cerealíferos haviam sido bons, a área cultivada aumentara e a pecuária beneficiara também. É que, segundo os cálculos dos fisiocratas, "hum alqueire de terra cultivado produz mais folhagem para sustento do mesmo gado, do que dois ou tres de pasto». Era, a defesa da sobreposição da lavoura e da pecuária, em vez da tradicional justaposição.

Mais: os «negociantes» tinham a inabalável convicção de que, pela «franqueza» do comércio (para todos e ao longo de todo o ano), a produção aumentaria, as jornas seriam mais elevadas, a alimentação, a habitação e o bem-estar geral melhorariam. Enfim, chegaria o «progresso» aos Açores.

Reconstituímos com a ajuda, sobretudo, de documentação publicada pelo «Archivo dos Açores» a experiência (talvez prematura) do liberalismo económico e da fisiocracia nas ilhas açorianas. Reparámos, contudo, que tal liberalismo tinha a restringi-lo uma importante ressalva: o cumprimento do «Pacto Colonial».

É verdade: que os «atravessadores» eram oportunistas e egoístas; que eram perfeitamente aleatórios os cálculos da «reserva» dos grãos para consumo local, além da aplicação da medida ser com certeza discriminatória; que não eram respeitadas, quando não eram mesmo desvirtuadas, as determinações legislativas emanadas do Governo Central; que a elite terratenente-mercantil, com o conluio da Igreja local, se aproveitava de uma mão-de-obra barata, sustida até ao limite da sua necessidade de emigrar... 
Mas, também não é menos verdade que só, teoricamente, o comércio externo dos Açores era livre, já que só poderia ter como destinos possíveis o Reino e a Madeira. Nestas circunstâncias limitativas, como é que poderia resultar a fórmula propagandeada, por exemplo, pelo desembargador José Acúrsio das Neves, nas suas Variedades sobre objectos relativos ás Artes, Commercio, e Manufacturas, consideradas segundo os Principios da Economia Politica: «[...] o commercio he providente, deixemo-lo respirar, e confiemos nelle»? É que, se para os fisiocratas o combate aos monopólios por parte dos «atravessadores» era quase um dogma, por, sobretudo nos bons anos agrícolas, com a liberdade do comércio, se conseguirem bons preços, bons rendimentos, boas jornas e capital para mais investimentos, também não é menos verdade que, com o «Pacto Colonial» a persistir, o monopólio passava das mãos dos «atravessadores» para o Estado. Deste modo, soavam a falso não apenas as doutrinas económicas, mas sobretudo a aplicação às ilhas açorianas dos estatutos de «adjacentes ao Reino de Portugal» (pelo alvará de 26 de Fevereiro de 1771) e de «provincias do Reino» (por decreto de 28 de Outubro de 1828).

Quanto à primeira contradição, José Acúrsio das Neves, em 1800, não se iludirá que as ilhas dos Açores constituíam mesmo «uma colónia e não um Estado independente», pelo que era a esta luz que deveriam ser examinadas as suas relações com a Metrópole. Assim, sob esta perspectiva: "Persuadem pois os princípios gerais que deve ser ilimitada nas Ilhas dos Açores a liberdade do comércio dos grãos, mas insta uma razão particular para que ela seja restringida ao comércio com a Metrópole [o exclusivo comercial], muito mais porque essa mesma Metrópole, não tendo no seu próprio país segura a subsistência dos seus habitantes, precisa de receber grão estrangeiro». Logo, a legislação do alvará 
de 26 de Fevereiro de 1771, «enquanto se dirige a favorecer as exportações para a capital do Reino e da Madeira» teria que ser considerada por ele como «muito sábia»e, ainda mais, se tivessem sido extirpadas todas as restrições a esse comércio ${ }^{12}$. Mas, que diria ele quanto ao entendimento do estatuto de ilhas «adjacentes ao Reino de Portugal» e contido no mesmo diploma. Não explica e aqui é que residida muito do equívoco sobre a autonomia açoriana. É que no referido alvará o sentido do conceito «adjacente» está bem explicitado: «se reputam como partes, e verdadeiras Provincias deste Reino».

Seriam? Obviamente que não! 